Thor-André Skrefsrud

https://doi.org/10.26881/pwe.2018.42.08

ORCID: 0000-0001-9954-235X

Inland Norway University of Applied Sciences

thor.skrefsrud@inn.no

\title{
Intercultural learning in diverse schools: obstacles, opportunities, and outlooks
}

\begin{abstract}
Summary
The emergence in recent years of the concept of intercultural learning has raised questions about how the notion relates to a pedagogy that fosters openness, exploration, and critical thinking. In this article, the author provides a critical examination of a conventional understanding of intercultural learning to clarify its construction and to elucidate its instructional implications. Central to this alternative is a pedagogy that acknowledges students' former experiences and competencies without making cultural predictions. Instead of reducing the process of understanding to a technical issue, this paper advocates the integration of intercultural learning in schools by connecting the curriculum to students' lives and identities. This paper ends with a consideration of the future prospects of intercultural learning, suggesting more research on how intercultural learning actually takes place in schools and society.
\end{abstract}

Keywords: intercultural learning, intercultural communication, multicultural education, cultural diversity

\section{Introduction}

In countries around the world, migration and other aspects of globalization continue to transform societies. Although it could be argued that many countries have long been diverse, the increase in ethnic, cultural, linguistic, and religious complexity has posed new challenges for educators and policymakers. While education is often charted for the mainstream population, findings from the Organization for Economic Cooperation and Development (OECD) have emphasized the fact that minority students underachieve academically in many countries (OECD 2015). Governments are therefore required to rethink and explore new strategies and structures that boost achievement among students with an immigrant background, in addition to the mainstream students (Cummins 2018).

A related challenge is the public response to increased migration. The international migration into and within Europe has not necessarily enhanced peoples' cosmopolitan outlooks. Instead, it has led to increased skepticism and even in some cases to hostility toward immigrants and refugees. Although the number of immigrants has fallen sharply in recent years, public anger seems to have not. European societies are thus in need of pedagogical measures to bring about equitable changes in the educational system that critically address the reinforcement of cultural stereotypes that build distorted images of the stranger. More 
than ever, schools are faced with the challenge of raising academic achievement for all and enabling children to live peacefully together, regardless of cultural, ethnic, linguistic, or religious background (Bartolo \& Smyth 2009).

For these reasons, many countries have put intercultural learning high on the educational agenda (Darling-Hammond \& Lieberman 2012; OECD 2014; Ogrodzka-Mazur 2018; Taguma, Shewbridge, Huttova, \& Hoffman 2009). As societies become increasingly multilingual and multiethnic, so does the importance of promoting knowledge, skills, and attitudes that enable children to enter into contact with the other, to transcend borders, and to learn to live with differences. Hence, schools need to provide students with relevant competencies in order to prepare them for living and working in a global and diverse context.

Despite governmental initiatives, however, education is struggling with appropriate ways to approach increasing diversity (Cochran-Smith 2013; Cochran-Smith, Davis, \& Fries 2004). This has irked many teachers and researchers, including me. On the one hand, proposed curricula, at least explicitly, expect teachers to chart more equitable opportunities for all children. On the other hand, being part of the educational system, we all need to challenge the often imbedded devaluation of identity that students of minority background may experience (Cummins 2018). As in Norway, for example, an OECD review states that Norwegian schools need to be "more responsive to linguistic and cultural diversity" and that "teachers are not yet well prepared to adapt their teaching to the specific needs of immigrant students" (Taguma et al. 2009: 8). This corresponds with an international trend documented in Darling-Hammond \& Lieberman (2012). In a comparison of teacher education in Europe, America, and Asia, this study found that "recurring themes for improvement [...] include strengthening connections between theory and practice and developing teachers' capacities to teach diverse learners" (Darling-Hammond \& Lieberman 2012: 159).

These findings from research and the OECD thus suggest that teacher preparation may not be as effective as it should be, even giving significant attention to diversity issues. With this background, it is necessary to continue discussing how schools may create learning environments that stimulate the acquisition of knowledge, attitudes, and skills necessary for interacting with people, different experiences, and world views.

In this article, I contribute to this discussion by elaborating how the concept of intercultural learning could be understood within a diverse school context. In the first part of the paper, I turn to the work in Nussbaum (1997) on the cultivation of communicative competencies. This makes a starting point for discussing a well-established argument that we often hear from the media, policymakers, and even scholars that intercultural learning is about increasing the familiarity of the unknown by deciphering cultural codes through in-depth knowledge about different cultures. In the second part of this paper, I propose an alternative approach to intercultural learning, using the works of John Dewey and Paulo Freire as a frame of reference. I end the article by reflecting upon the future prospects of intercultural learning in a context where cultural stereotypes and xenophobia are challenging the openness and willingness to explore differences. 


\section{Intercultural learning: introductory remarks}

Intercultural learning is about learning how to live together in a diverse society. By combining "intercultural" and "learning," the term aims to explain pedagogically how people with different ethnic, cultural, and linguistic backgrounds can get along and learn from each other in a process of mutual understanding (Horst 2006). While learning can be described as the process of acquiring new knowledge, attitudes, skills, and behaviors, the term intercultural refers to what happens in the encounter between people from different cultures (Burbules 2000). Intercultural learning thus refers to a transforming communicative interaction between parties holding differing views. Hence, used pedagogically, intercultural learning often describes the process of acquiring new insights, knowledges, and perspectives in a diverse educational context.

Somewhat similar, Martha C. Nussbaum has elaborated on what it means to live as a citizen in a diverse context, which can be useful in this regard. Nussbaum (1997) introduces what is called "essential capacities" as a key factor for establishing intercultural learning. The first capacity that Nussbaum (1997) highlights is the ability to critically examine oneself and one's own traditions (Nussbaum 1997). According to Nussbaum (1997: 9), this means "[...] a life that accepts no belief as authoritative simply because it has been handed down by tradition or become familiar through habit".

Second, for intercultural learning to emerge, people need the ability to see themselves not only as members of a local group, but also as bound to other human beings through mutual responsibilities and concerns (Nussbaum 1997). In Nussbaum (1997: 10), this requires a "[...] call to our imaginations to venture beyond narrow group loyalties and to consider the reality of distant lives". The third capacity is closely related to the two others and involves the ability to sympathize what it might be like to be in the shoes of another person. Nussbaum (1997: 11) calls one to be an intelligent reader of a person's story, which involves an empathetic, narrative imagination of what the other person's wishes, emotions, and desires might be.

From this, we see that the concept of intercultural learning stands in contrast to a pedagogy that fails to recognize students' cultures and languages. Historically, in many countries, including Norway, the lack of cultural recognition in education has reflected the wider society's devaluation of language and culture other than those of the dominant group (Cummins 2001; Engen 2014). This has certainly been the case for indigenous peoples who often have been disparaged by colonial power. In Norway, the Sami population was subject to strong assimilation (Darnell \& Hoëm 1996). In addition, the cultural and linguistic identities of other groups and communities, such as the Kven people and the Forest Finns, were never considered a part of the school culture (Moen 2009; Niemi 2003).

The current anti-immigration discourses in many European countries similarly illustrate this pattern. Within such discourses, migrant students' home cultures and languages are constructed as impediments to learn the new language and to integrate properly into the new country of residence. Minority students and their families are seen as culturally, 
linguistically, and socially deprived and in need of repair (Baker \& Wright 2017). While students have unsurprisingly disengaged themselves from schooling under these conditions, their non-participation has frequently been interpreted as a lack of academic interest or ability. Low academic achievement for these students may therefore easily become a self-fulfilling prophecy (Cummins 2001).

As Nussbaum reminds us, however, intercultural learning is about acquiring certain knowledges, skills and attitudes that may be helpful for a person and community to combat stereotypes and misconceptions and instead establish understanding across ethnic, cultural, and religious differences. I will further show how this starting point may help us critically examine a conventional, widespread, but yet rather superficial way of perceiving intercultural learning as the process of making the strange familiar.

\section{A conventional understanding}

Often, intercultural learning is associated with the process of getting to know new cultures and practices - often exotic and strange ones - in order to understand them better. Such a concept is in most cases followed by the best of intentions. Nevertheless, intercultural learning is often built on the somewhat problematic assumption that cultures can be described and understood according to an essence that characterizes each specific cultural community. Furthermore, it claims in-depth knowledge will create tolerance and understanding of the systems' content and functions, and of the persons who belong to the different collectives. Conceptualizing intercultural learning in this way, the notion is primarily about making the stranger more familiar by acquiring cultural knowledge about distant customs and world views.

In the field of intercultural communication, we find that intercultural learning is most often understood as a coding and decoding filter that makes the message in the communication process understandable (Samovar, Porter, McDaniel, \& Roy 2017). This has also been the case for a widely used framework for providing cultural learning, developed by Geert Hofstede and his team in a Dutch context (Hofstede 1980; Hofstede, Hofstede, \& Minkov 2010). Based on surveys of employees in companies in the East and the West, Hofstede (1980) developed a model where differences in culture have been plotted along five dimensions: power distance, masculinity vs. femininity, long-term orientation vs. short-term thinking, individualism vs. collectivism, and uncertainty avoidance (Hofstede 1980; Hofstede et al. 2010). According to Hofstede, the model then offers a basis for predicting cultural differences between people. To learn from other people holding different views than oneself, this requires a knowledge of the essence of the specific cultures that communicate with each other.

The instructional implications of such a thinking would be that teachers and students, in order to learn from others, must have in-depth knowledge of the cultural characteristics from the various ethnic groups represented in the classroom. According to Gay (2002: 111), this implies that the "[...] intellectual thought of students from different ethnic groups 
is culturally encoded in that its expressive forms and substance are strongly influenced by cultural socialization". Hence, for intercultural learning to take place, teachers and students must be able to decipher the codes of various cultures and use this information to get to know and relate to each other better, exploring what kind of differences that make communication difficult. Likely, intercultural learning is meant to happen as the teacher informs, explains, and deepens for the students how different cultural backgrounds, traditions, and world views are the structured manifestation of human behavior in social life.

\section{The limitation of a conventional approach}

Obviously, to know the history and background of minorities is highly important for anyone who wishes to increase the understanding of minority issues to promote tolerance and understanding. However, to speak of intercultural learning as the process of assessing in-depth knowledge of cultural characteristics from ethnic groups may restrict children if it does not provide adequate space for the dynamics and complexity of cultural identity. Identifying cultural essence and drawing clear boundaries between cultures are extremely difficult because cultures are being formed and constantly renewed in a process of cultural exchange and transformation (May \& Sleeter 2010). Cultures today are therefore much more interrelated hybrids and in a constant process of change, far more than that expressed by the conventional paradigm.

This became evident in a study I conducted some years ago. ${ }^{1}$ Here, I met a young student named Assim. He was born in Iran, but had moved with his family to Turkey at the age of 6 and to Norway at 11. Even though Assim was born in Iran, went to school there, and spoke Farsi at home, it became clear that this family background was not something he wanted to be associated with in class. Instead, the geographical place of transit, Turkey, became important for Assim. He openly disliked the weekly hours of bilingual teaching in the Persian language and wondered why Turkish, which he was familiar with from his years in transit, could not be the language studied. When the other students were represented with their flags on the school's Christmas tree, Assim asked why there had to be an Iranian flag on the school's Christmas tree. Hence, Assim saw himself being from Turkey, not Iran (Skrefsrud 2018: 53-54). From this, we see that labeling students with specific cultural backgrounds can be difficult. Even more seriously, cultural differences may be reinforced in ways that put restrictions on the students: who they are and are able to be in the community of learners.

Considering Nussbaum's theoretical thinking (1997), she takes direct exception to the idea that people are products of their culture. According to Nussbaum, people are seldom affiliated to one local group, but culturally bound to other human beings. On the one hand, she reminds us that a person's cultural identity is related to collective identities, such as

1 This study was conducted as part of a three-year (January 2013-December 2015) Nordic research project, Learning Spaces for Inclusion and Social Justice: Success Stories from Immigrant Students and School Communities in Four Nordic Countries. 
ethnicity, social background, religion, sexual orientation, and gender. On the other hand, cultural identity is hybrid and constantly changing. A person can be Lebanese with Polish citizenship, and at the same time use English in daily communication, prefer television programs in Arabic, have a Christian faith, etc. (cf. Sen 2006). The aspects of an identity one wishes to stress will vary according to the social context and is even intensified with experiences of global migration, such as we saw in the example with Assim.

Furthermore, Nussbaum (1997) reminds us that intercultural learning is about involving oneself in another person, that is, to understand or feel what another person is experiencing and to place oneself in another's position. This way of approaching cultural differences is quite different from what we see in a conventional approach to intercultural learning. Within the conventional concept, cultural differences are seen primarily as hindrances for effective learning. Differences are constructed as barriers to interaction, and intercultural learning is the tool for removing strangeness by gradually making the unknown more familiar. By accessing increasing amounts of knowledge about the other, the aim is to overcome the other's strangeness, not to sympathize with and perhaps learn from it.

The conventional way of conceptualizing intercultural learning therefore runs the risk of not taking differences seriously and not respecting the integrity of people. Moreover, an instructional implication may be that a conventional way of approaching intercultural learning is missing out on a number of possibilities. When differences are reduced to something that can be predicted through cultural knowledge, the process of intercultural learning becomes a closed process with a limited number of outcomes. The risk is therefore that one may lose sight of the potentially innovative, unpredictable, and creative nature of intercultural encounters and the learning that may emerge when different people interact.

In the following sections, I therefore pursue an alternative way of approaching intercultural learning. Building on Nussbaum's thinking and taking inspiration from the work of Dewey and Freire, I aim to contribute to this discussion by suggesting a different way of thinking than that of the conventional approach. Two aspects are central to this alternative: first, the connection of students' lives and identities to the curriculum, and second, the transformative potential of a context-sensitive pedagogy.

\section{Connecting curriculum to the everyday lives of children}

An early appeal to a pedagogy that recognizes students' differences as resourceful, as pedagogically viable and valuable, can be found in Dewey's work on the integration of children's former experiences and knowledges in the process of learning. In Experience and Education, Dewey (1963) outlines a distinction between what he saw as a conventional approach to education and a new, experience-oriented model. Using the historical context of migrant rural children attending the urban schools of Chicago as his frame of reference, Dewey criticized traditional schooling for being teacher- and not student-centered, which largely ignored the central role the students' own experiences may have as an intellectual starting point for learning. According to Dewey (1963), teachers were first and foremost 
providers of a static body of knowledge, transmitting what the curriculum prescribed as relevant information, while students were pictured as passive recipients, or empty buckets to be filled. What followed from this is that children's learning at school was conceived of as a distinct experience, separated from other experiences or arenas of learning in the wider society.

In opposition to a traditional (and a progressive) view on education, Dewey outlined a new philosophy of experience, emphasizing the individual's participation as constitutive for gaining new knowledge. According to Dewey (1963), children were better served if they took an active part in the process of their own learning. Within traditional education, however, no demands were made where "the teacher should become intimately acquainted with the conditions of the local community, physical, historical, economic, occupational, etc., in order to utilize them as educational resources" (Dewey 1963: 40). For Dewey, a sound educational experience instead involved continuity and interaction between the learner and what is learned. Above all, teachers "should know how to utilize the surroundings, physical and social, that exist so as to extract from them all that they have to contribute to building up experiences that are worthwhile" (Dewey 1963: 40).

Not surprisingly, in Dewey's pedagogy there are two subjects of particular importance to activate children's experiences: geography and history (Dewey 1961). For the students, learning about the local community was important as it activated former experiences and therefore recognized students' experiences as relevant for the curriculum. Even more important, it motivated students to seek new understanding and provided a base for interpretation. Ultimately, Dewey's intention was to create a relationship between the students' everyday lives and places and the curriculum (cf. Kitchens 2009). In this way, Dewey provided the ground for a pedagogy that does not see differences as something that interfere or disturb the process of learning, but as something that should be acknowledged and recognized as valuable, both in regards to the individual student and for the learning community as a whole.

How a Dewey-inspired pedagogy looks in schools may be illustrated by an example from the aforementioned Nordic study on inclusive learning spaces. As part of a larger ethnographical fieldwork, I observed a sixth grade teacher working at a diverse urban primary school in the east of Norway. At the time of the study, the school had 430 pupils from grades one to seven, and approximately 100 employees. More than one-fifth of the children spoke a language other than Norwegian at home. Many of them were speakers of Somali, whereas others spoke Arabic, Dari, Swahili, Amharic, Tigrinya, Polish, and Romanian. In total, 39 different languages were spoken at the school.

Observing the teacher in language lessons during a period of 14 days, it became evident that the students' former knowledge and competencies were incorporated in the curriculum. An example was a two-hour lesson on Norwegian grammar, where the teacher introduced a noun-game in the classroom. First, she put 10 items from the classroom on a tray, asking the children to look carefully at them for about 30 seconds. She then covered the tray with a blanket and took away one item, asking the children to spot what was 
missing. A twist in the game, however, was that the students should give the name of what was missing in as many languages as possible. The class would then repeat the name of the item in those different languages, as well as learn an example on how to use it orally in a simple sentence. During the lesson, it became clear the two newly arrived students Jamilah and Adrian - had an advantage compared to their classmates, who spoke Norwegian and some English. Jamilah spoke both Somali and Swahili fluently - the latter she had learned in transit during her time at a refugee camp in Kenya - in addition to Arabic, some Norwegian, and English. Adrian spoke Romanian and German, as well as Russian, which he had learned from his father, and some Norwegian and English. Hence, Jamilah and Adrian were not bilingual, but penta-lingual, or better yet, trans-lingual, a competence that became visible to the whole class.

From this, we see that the teacher was able to draw a link between prior knowledge, migrant experiences outside of the classroom, and the present classroom situation. For the newly arrived students struggling to learn the Norwegian language, the teacher created a space where differences were valued. Not only were the students' linguistic competencies given positive attention from the teacher and the rest of the class, but their differences were acknowledged as part of the class's learning. The example thus leads me to my last point, that of emancipation and transformation. As I will show, recognizing differences in the classroom also has an empowering and transformative potential. This is what Freire's liberation pedagogy may help us to understand better.

\section{Emancipation and transformation}

Dewey's main concern was not that of fostering social transformation or individual emancipation. Instead, he saw children's previous knowledge, experiences, and skills primarily as a medium for learning. As Kitchens (2009) and others have emphasized, this primary focus on motivation makes it necessary to supplement Dewey's thinking with a perspective of emancipation and transformation. A pedagogical thinking that acknowledges differences also has the potential to examine experiences and prior knowledge in a wider social and historical perspective, not merely as motivational starting points for learning.

This ambition was precisely what Freire aimed to realize in his pedagogy of liberation (Freire 2005; Shor \& Freire 1987). Beginning with students' experiences, Freire's thinking builds a bridge between a situated and critical pedagogy. According to Freire, "[...] this turn towards subjective experience must also include a global, critical dimension" (Shor \& Freire, 1987: 4). This means that subject themes should not be reduced to a technique, "[...] simply to confirm the status quo or motivate students" (p. 104). Instead, students' experiences should be presented and studied in ways that seek to transcend the given. For Freire, starting with students' local knowledge and experiences and moving from the known to the unknown was not only about having children pursue their own propensities for learning and intellectual growth. A context-based pedagogy should also affect and perhaps even alter the students' experiences (Freire 2005). Thus, while Dewey emphasizes 
the significance of context, Freire reminds us that the contextual starting point also may create a space for action, intervention, and even transformation.

For the students in the Nordic study presented above, the activation of their wider linguistic repertoire can be seen as a way to counteract a pedagogy that does not take differences seriously. Moreover, by building on their language skills, the students were given an empowered voice that positions the pedagogical praxis in contrast to the mainstream monolingual classroom, where differences are overlooked, as well as to contemporary discourses that construct students' cultures and languages as deficits or deficiencies to be overcome by the school. This corresponds with Freire's call for changing the context: "Indeed, the interests of the oppressors lie in 'changing the consciousness of the oppressed, not the situation which oppresses them"' (Freire 2005: 74). To acknowledge the values, experiences, and competencies that a diverse student body brings to the mainstream classroom, the whole institution needs to adapt to change.

From Dewey and Freire, we see that intercultural learning can take place when the often-hidden richness of the resources and competencies of children and youth are made visible in the classroom. As Freire (2005) reminds us, "[1]iberating education consists in acts of cognition, not transferals of information" (p. 79). In this way, a pedagogy that allows for intercultural learning to emerge, is critically challenging a practice where the teacher "[...] fills the students with the contents of his narration - contents which are detached from reality, disconnected from the totality that engendered them and could give them significance" (p. 71). Understood in such a perspective, intercultural learning distances itself from a conventional approach that reduces differences to obstacles on the way to effective communication. Instead, intercultural learning is about acknowledging the presence of differences, aiming to explore other patterns of thought, ideas, and perspectives for understanding more about oneself and the other. Nussbaum, Dewey, and Freire can help us to see this more clearly.

\section{Conclusions and outlooks}

The scope of this paper has been to critically examine a conventional way of understanding intercultural learning and in contrast suggest a different way of thinking about learning from differences. While a conventional approach sees differences as obstacles on the way to understanding, an alternative approach presupposes the inclusion of voices from the margins into the mainstream (Dewilde \& Skrefsrud 2016). At the core of intercultural learning is thus a fundamental recognition of the cultural and linguistic competencies of all children and their families. This includes a wider understanding of curriculum, where cultural differences and issues of diversity are integrated in practices and teaching rather than existing on the periphery.

For the teacher aiming to provide intercultural learning in the classroom, it is thus important to be aware of children's wide variety of life experiences. To establish space for children to explore their complex identities, the teacher must recognize and acknowledge 
the complexity of the histories, legacies and world views of the students. As I have argued in this paper, a conventional understanding of intercultural learning is therefore less suitable as a model for understanding the process of encountering the strange.

So, then, what are the prospects for intercultural learning in a school and society characterized by increasing diversity? Although the interrelations of cultures through migration and diasporas in European societies is an old phenomenon, people of today are brought in contact with each other in new ways. As human beings living in a time of globalization, we are highly involved with each other, creating communication across differences. Nevertheless, negative cultural stereotypes, xenophobia, and hostility toward foreigners are threatening the willingness and openness to explore differences. In times like this, the solution is not the conventional paradigm. Understanding intercultural learning in a conventional way favors essence and categorical stereotypes over openness, respect, and curiosity. Paradoxically, we may then increase the risk of conflict more than promoting understanding and new insights.

The work from Nussbaum, Dewey, Freire, and others may help us to think differently about this issue. The alternative notion of intercultural learning can thereby represent a significant counter voice against discourses that devalue and distort the languages, cultures, and identities of students both in school and in the wider society. Hopefully, this may inspire others to conduct further research on how intercultural learning takes place how different people whose biographies do not necessarily overlap, interact and communicate with each other while not reducing the other's strangeness. This will be a challenge for future research, but a highly important and motivating one.

\section{References}

Baker C., \& Wright W.E. (2017), Foundations of Bilingual Education and Bilingualism (6th ed.). Blue Ridge Summit, PA, USA, Multilingual Matters.

Bartolo P., \& Smyth G. (2009), Teacher Education for Diversity. In: A. Swennen \& M. v. d. Klink (Eds.), Becoming a Teacher Educator. Theory and Practice for Teacher Educators. New York, Springer.

Burbules N.C. (2000), The Limits of Dialogue as a Critical Pedagogy. In: P.P. Trifonas (Ed.), Revolutionary Pedagogies. Cultural Politics, Instituting Education, and the Discourse of Theory. New York, Routledge.

Cochran-Smith M. (2013), Trends and Challenges in Teacher Education: National and International Perspectives. In: A.-L. Østern, K. Smith, T. Ryghaug, T. Krüger, \& M.B. Postholm (Eds.), Teacher education reserach between national identity and global trends. Trondheim, Akademika.

Cochran-Smith M., Davis D., \& Fries K. (2004), Multicultural Teacher Education. Research, Practice, and Policy. In: J.A. Banks \& C.A.M. Banks (Eds.), Handbook of Research on Multicultural Education. San Francisco, Jossey-Bass.

Cummins J. (2018), Teachers as Knowledge Generators: Pushing the Boundaries at Thornwood Public School. In: A.M.V. Danbolt, G.T. Alstad, \& G.T. Randen (Eds.), Litterasitet og 
flerspråklighet - muligheter og utfordringer for barnehage, skole og laererutdanning. Bergen, Fagbokforlaget.

Darling-Hammond, L., \& Lieberman, A. (2012). Teacher Education Around the World. Changing Policies and Practices. New York: Routledge.

Dewey J. (1961), Democracy and education: an introduction to the philosophy of education. New York, The Macmillan Company.

Dewey J. (1963), Experience and education. London, Collier MacMillian Publisher.

Freire P. (2005), Pedagogy of the oppressed. New York, Continuum.

Gay G. (2002), Preparing for Cultural Responsive Teaching. "Journal of Teacher Education", 52(2).

Hofstede G. (1980), Culture's consequences. International differences in work-related values. California, Sage.

Hofstede G., Hofstede G.J., \& Minkov M. (2010), Cultures and organizations: software of the mind: intercultural cooperation and its importance for survival (3rd ed.). New York, McGraw-Hill.

Horst C. (2006), Interkulturel padagogik. Vejle, Kroghs forlag.

Kitchens J. (2009), Situated pedagogy and the situationist international: countering a pedagogy of placelessness. "Educational Studies", 45(3).

May S., \& Sleeter C.E. (Eds.) (2010), Critical multiculturalism: Theory and praxis. New York, Routledge.

Nussbaum M.C. (1997), Cultivating Humanity. A Classical Defence of Reform in Liberal Education. Cambridge, Massachusetts, Harvard University Press.

OECD (2014), Education at a Glance. Paris, OECD.

OECD (2015), Helping immigrant students succeed at school - and beyond. Paris, OECD.

Ogrodzka-Mazur E. (2018), Intercultural Education in Poland: Experiences, Problems and Prospects. In: O.B. Cavero \& N. Llevot (Eds.), New Pedagogical Challenges in the 21st Century. London, IntechOpen.

Samovar L.A., Porter R.E., McDaniel E.R., \& Roy C.S. (2017), Communication Between Cultures 9th Edition. Bosten, Cengage Learning.

Shor I., \& Freire P. (1987), A pedagogy for liberation: Dialogues on transforming education. New York, Bergin and Garvey.

Skrefsrud T.-A. (2018), Barriers to intercultural dialogue. "Studies in Interreligous Dialogue", 28(1).

Taguma M., Shewbridge C., Huttova J., \& Hoffman N. (2009), OECD Reviews of Migrant Education. Paris, OECD. 